Journal of Helminthology, Vol. II., No. 2, April, 1924, pp, 95-96.

\title{
On the occurrence of Nematodes in the excretory duct of a Cestode Inermicapsifer hyracis.
}

\author{
By Jean G. Baer. \\ Zoological Department, University of Neuchâtel, Switzerland.
}

While examining some sections of a specimen of Inermicapsifer hyracis (Rud.), we came across an extremely interesting and, what we believe to be, a unique occurrence.

In the ventral excretory duct of this Cestode, we found two specimens of what we take to be larval Nematodes; the one shown in the photo-

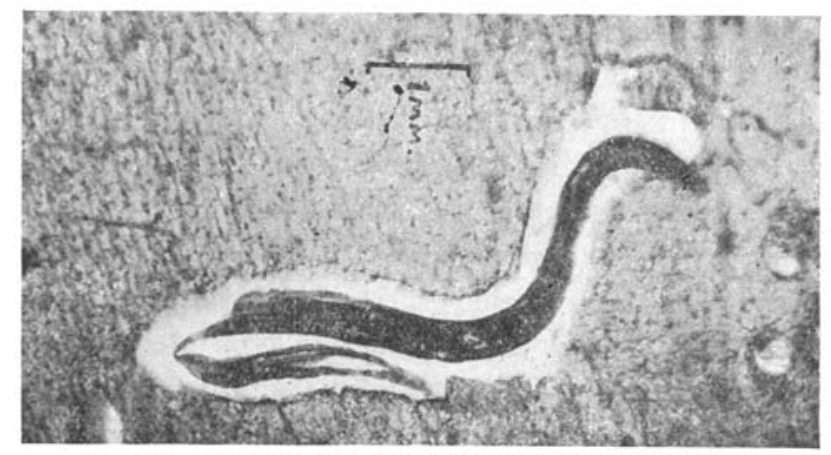

Photo-micrograph showing the Nematode in the ventral excretory duct of Inermicapsifer hyracis (Rud.).

micrograph is free in the lumen of the main duct, and the other is forcing its way into one of the secondary ducts. As there is no visible sign that the presence of these Nematodes has been the cause of any local irritation, the cuticula lining the duct, as well as the latter presenting a perfectly normal appearance, and the fact that the worm in the main duct has been able to curl itself round, lead us to believe that these two worms were moving about freely in the excretory ducts of the Cestode.

We have not been able to determine with certainty to which genus these worms ought to be referred, as the sections are not in a horizontal plane. However, it can only be one of the five genera found in the Hyrax, viz. : Physaloptera (Rud.), Crossophorus Ehrenb., Oxyurus Rud., Deletro- 
cephalus Dies, and Hoplodontophorus Turner. We hardly think it possible that we have before us a member of another genus other than those already mentioned, as the material we examined formed part of that described by Miss M. Turner, B.Sc. (1922). We have searched the literature concerning the presence of accidental " parasites " in Cestodes, and apart from an unpublished case of Prof. Fuhrmann, that of two Distomes encysted in the parenchyma of a larval Ligula avium Bloch, we are unable to find any cases to be added to the list given by Braun (1900). From this list it will be seen that there are only two cases reported of Nematodes as accidental " parasites" of a Cestode.

The first case, that of Grassi \& Parona, is of no special interest, as we feel certain that many such like cases have been found since and not reported. Monticelli's case is of more interest in that we have a larval Nematode encysted in a Cestode. This seems to be the most common case, and is of the same nature as those of Riggenbach and Fuhrmann. The most plausible explanation seems to us to be that the larval " parasite" being in the wrong host, has mistaken the parenchyma of the Cestode for the gut-wall or other suitable and normal organ.

Our own case is of special interest, in that we have a larval Nematode, which we believe to be in its normal host (Hyrax), living free in the excretory system of a Cestode. With regard to the mode of infection, we suppose owing to its size, viz. : $1 \mathrm{~mm}$. long and $.04 \mathrm{~mm}$. in diameter, that the nematode penetrated via the excretory pore.

A short time ago there appeared a review by $\mathrm{Ph}$. Dolfuss (1923) of a paper by Southwell \& Prashad, dealing with Ilisha parthenogenetica S. \& P. The reviewer put forward the idea that these parthenogenetic "buds " are nothing more than sporozoon cysts; we do not, however, accept this interpretation.

\section{REFERENCES.}

Braun, M., 1900._-“Cestoda" Bronn's Thierreich, p. 1614.

Dolfuss, R. Ph., 1923.-_ "Sur un Sporozoaire parasite de Cestode." Ann. Parasit. Vol. L., p. 20.

Grassi \& Parona, 1897.- "Sovra la Taenia crassicollis." Atti. soc. Ital. Sc. Nat. Milano. Vol. XXII., pp. 207-209.

Monticellt, F.S., 1891.- "Notizie su di alcune specie di Taenia." Boll soc. di Nat. in Napoli. Vol, v., pp. 151-174.

Riggenbach E., 1896.- “Das genus Icthyotaenia." Rev. Suiss de Zool. Vol. IV., p. 239.

Turner, M., 1922.- "On some helminth parasites of an East African Rock Rabbit." Trans. R. Soc. Trop. Med. and Hygiene. Vol. xv., pp. 182-189. 